\title{
Experimental Investigation of the Micro-hardness of EN-31 Die Steel in a Powder-Mixed Near-Dry Electric Discharge Machining Method
}

\author{
Sanjay Sundriyal ${ }^{1}$-Vipin ${ }^{1}$ - Ravinderjit Singh Walia2,* \\ 1Delhi Technological University, India \\ 2Punjab Engineering College, India
}

The Powder-Mixed Near-Dry Electric Discharge Machining (PMND-EDM) methodology has proven to be efficient in terms of machining rate, surface morphology, and environmental friendliness, unlike traditional EDM. In this study, the presence of a conductive metallic powder (zinc) in the dielectric medium was responsible for changing the topography of the workpiece (EN-31) and resulted in a higher micro-hardness value of the machined component. In this research, an approach has been made to optimize the significant process parameters by using a Taguchi $L_{9}$ orthogonal array (OA) to obtain machined components with higher values of micro-hardness, which was measured in terms of Vickers hardness HV. The selected process parameters were tool diameter, mist flow rate, metallic powder concentration, and dielectric mist pressure. By introducing foreign particles (metallic powder), the topography of the machined products has been improved, and the micro-hardness value was found to be enhanced. The confirmation experiment was performed for optimal process parameter settings, and the enhanced microhardness value was found to be $506.63 \mathrm{HV}$ in the machined EN-31 die steel.

Keywords: electric discharge machining, powder, near-dry, micro-hardness, optimization

\section{Highlights}

- The PMND-EDM method of machining at optimum input process parameters leads to the generation of machined parts with higher micro-hardness values.

- It was observed that optimum parameter condition at A1, B2, C3, and D3 were most dominant in achieving the maximum micro-hardness of the machined EN-31 Die steel workpiece. Confirmation experiments revealed that the highest value of microhardness was found to be $506.63 \mathrm{HV}$ at the optimized input process parameters.

- The predicted optimal range of confidence interval of conformation experiments (CICE) for micro-hardness was: $445.05<$ microhardness < 596.35. The $95 \%$ conformation interval of the predicted mean for micro-hardness was: $482.88<$ micro-hardness $<558.52$.

- A layer of hard zinc carbide hard was deposited over the surface of the machined sample, which leads to a higher value of micro-hardness. The experimental results were validated by the confirmation of experiments, and the obtained output results were within the permissible results.

\section{INTRODUCTION}

Electric discharge machining (EDM) is a wellrecognized non-conventional machining method and has been widely used in creating complex geometries in dies and moulds. EDM uses electric-thermal energy conversion to remove material from the workpieces that were difficult to be machined by any other nonconventional machining method. Although EDM has been globally accepted in the manufacturing industries, undesirable characteristics such as pores, cracks, surface pits and holes in the machined components make this process quite inferior in terms of surface morphology. Several research works have been done to improve the morphology and microhardness values of the machined components using powder-additive EDM methodologies. There was an improvement in the capabilities of the EDM process via the addition of powder in the dielectric fluid of EDM [1]. The feasibility of a new type of hybrid powder-mixed near-dry electric discharge machining (PMND-EDM) was confirmed for the first time [2]. The die steel surface was modified with tungsten powder additives in the dielectric medium of EDM [3]. The surface morphology was improved with the addition of metallic powder as there was carbon deposition in the plasma, which also increased the micro-hardness by $100 \%$. The micro-hardness of SS (stainless steel) was enhanced using powder-mixed electric discharge machining [4]. It was seen that 25 $\mathrm{g} / \mathrm{l}$ concentration of titanium carbide $(\mathrm{TaC})$ powder in dielectric medium of EDM enhanced the surface characteristics and micro-hardness value of $1200 \mathrm{HV}$ was achievable. There was an improvement in the EDM performance on machining of Ti-6Al-4V by dispersing $\mathrm{SiC}$ particles (abrasives) in the dielectric medium with magnetic stirring mechanism [5].Other researchers successfully achieved improved hardness 
of the specimen surface due to the formation of $\mathrm{TiC}$ and $\mathrm{TiSi}_{2}$. A Cu-Mn tool made with powder metallurgy was used for machining die steel with the EDM process utilizing the Taguchi technique [6]. Microhardness was increased substantially for the machined samples under optimum experimental conditions. Evaluation for micro-hardness was carried out by using different powder metallurgy tools $(\mathrm{Cu}$ and $\mathrm{Mn})$. There was an improvement in micro-hardness by $93.7 \%$ by the formation of cementite, ferrite and manganese carbide phases in the machined workpiece samples by utilizing a composite tool. Experiments were performed based on the L25 orthogonal array design of experiment at five different levels [7]. The machining performances were evaluated in terms of micro-hardness of the EDMed Inconel 718 end product. In this paper, a novel optimization route (combining satisfaction function, a distance measure approach in conjugation with Taguchi's philosophy) has been introduced. Graphite powder-mixed dielectric was utilized to improve machining performance on Inconel 625 [8]. The micro-hardness of AISI H13 tool steel workpiece was improved by using a molybdenum-powder-mixed dielectric medium in the EDM process [9]. The migration of molybdenum and carbon particles leads to the formation of a white layer over the machined surface in the form of FeMo and MoxC, which was responsible for improved micro-hardness. A Taguchi L27 OA (orthogonal array) was utilized for optimization of process parameters and utilized chromium powder additive for experimentation on $\mathrm{H}-11$ die steel in order to increase micro-hardness of machined surface via powdermixed EDM [10]. Analysis of variance (ANOVA) was utilized along with empirical model for the optimization and prediction of micro-hardness. The Taguchi method was followed to obtain a combination of six process variables for achieving the best microhardness [11]. Under favourable conditions for microhardness, noteworthy enhancement in the percentages of carbon and tungsten was observed. The presence of hard tungsten carbide $\left(\mathrm{W}_{2} \mathrm{C}\right)$ and cementite $\left(\mathrm{Fe}_{3} \mathrm{C}\right)$ on the machined surface was related to the observed substantial increase in micro-hardness $(\sim 150 \%)$. A study on the machined surface of Inconel 718 by EDM was performed and observed that the powdermixed EDMed machined surface was enriched more with carbon element in comparison to normal EDM (without powder) [12]. This carbon enrichment further increased the micro-hardness of the machined component. The impact of $\mathrm{SiC}$ powder on the topography of the machined surface was studied, as was the deposition of particles and subsurface structures in PM-EDM of Ti-6Al-4V-ELI workpiece [13]. A unique material transfer mechanism exhibited better subsurface properties, such as harder and resolidified layer structure. The discharges established at the machining gap were very well balanced due to the introduction of powder particles, which resulted in improved surface properties. Taguchi's L18 mixed OA (orthogonal array) was utilized for the planning of experiments and selected machine process as well as tool parameters for study [14].Nanoparticles' high reactive surface area made better surface alloying in comparison to other tool materials and has displayed positive influence on micro-hardness on the machined surface. The generated carbides over the surface increased the micro-hardness to $912 \mathrm{HV}$. It was stated that the pyrolysis of the dielectric media was responsible for significant carbon migration at the machined surface [15]. Therefore, the EDMed specimen shows the existence of a carbon-rich surface (carbide layer). The formation of such a carbide layer results in increased micro-hardness of the specimen in comparison to that of the "as-received" parent material.

Although significant research have been performed regarding powder-mixed EDM, very limited research has been conducted in terms of parameter optimization for micro-hardness in field of PMND-EDM. Therefore a hybrid setup was developed to carry out the experiments for the desired output results. Taguchi $\mathrm{L}_{9} \mathrm{OA}$ was utilized for the design of experiments, which comprise four parameters at three different levels. The selected process parameters were tool diameter, mist flow rate, metallic powder concentration, and dielectric mist pressure. These selected parameters were selected based on previous literature review and their significance which affects the machining characteristics [16] and [17].

\section{METHOD AND EXPERIMENTAL}

The experimental setup was developed at Delhi Technological University, Delhi, India, as shown in Fig. 1. This developed setup was integrated with a Sparkonix 35A EDM machine. The setup comprises of mixing chamber (stainless steel) along with dielectric flow meter $(0 \mathrm{ml} / \mathrm{min}$ to $20 \mathrm{ml} / \mathrm{min})$ and pressure regulators. An air compressor (2H.P) has been used for the supply of pressurized dielectric mist. The mixing chamber was used for preparing a dielectric mixture of metallic conductive powder along with a minute amount of dielectric oil and high-pressure air supplied from the compressor. 


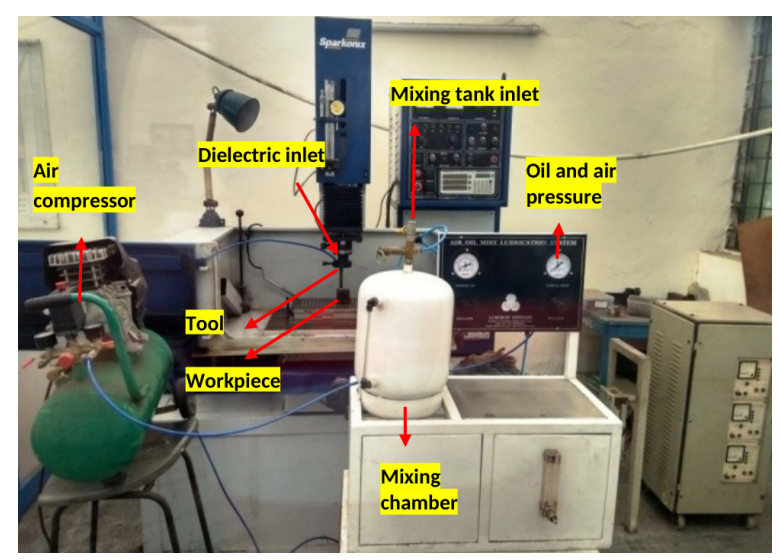

Fig. 1. Experimental setup for PMND-EDM

Table 1. Experimental conditions of selected process parameters

\begin{tabular}{|c|c|c|c|c|c|}
\hline Symbol & Process parameters & Unit & Level 1 & Level 2 & Level 3 \\
\hline$A$ & Tool diameter & $\mathrm{mm}$ & 2 & 3 & 4 \\
\hline$B$ & Mist flow rate & $\mathrm{ml} \mathrm{min-1}$ & 5 & 10 & 15 \\
\hline C & $\begin{array}{l}\text { Metallic powder } \\
\text { concentration }\end{array}$ & $\mathrm{g} \mathrm{l}^{-1}$ & 15 & 20 & 25 \\
\hline $\mathrm{D}$ & Mist Pressure & $\mathrm{MPa}$ & 0.4 & 0.5 & 0.6 \\
\hline \multicolumn{6}{|c|}{ *Values of other constant parameters: } \\
\hline \multicolumn{6}{|c|}{$\begin{array}{l}\text { Machining time } 10 \mathrm{~min} ; T_{\text {on }} 500 \mu \mathrm{s} ; T_{\text {off }} 75 \mu \mathrm{s} \text {; } \\
\text { Discharge current } 12 \mathrm{~A} \text {; Tool electrode Copper; Workpiece EN-31, } \\
\text { Metallic zinc powder }\end{array}$} \\
\hline
\end{tabular}

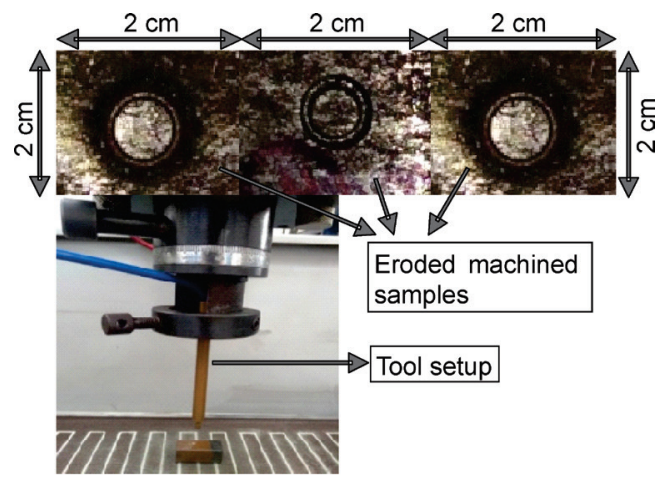

Fig. 2. Machined samples and tool setup for PMND-EDM

Table 2. Chemical composition and physical properties of workpiece (EN-31)

\begin{tabular}{lccl}
\hline \multicolumn{2}{c}{ Chemical properties } & \multicolumn{2}{c}{ Mechanical properties } \\
\hline Element & {$[\%]$} & Thermal conductivity [W m ${ }^{-1} \mathrm{~K}^{-1}$ ] & 44.5 \\
\hline Carbon & 0.90 to 1.20 & Hardness (HRC) & 63 \\
\hline Silicon & 0.10 to 0.35 & Yield stress [MPa] & 450 \\
\hline Manganese & 0.30 to 0.75 & Tensile strength [MPa] & 750 \\
\hline Sulphur & 0.050 & Density [kg m ${ }^{-3}$ ] & 7850 \\
\hline Phosphorus & 0.050 & Melting point $\left[{ }^{\circ} \mathrm{C}\right.$ ] & 1540 \\
\hline
\end{tabular}

The experimental conditions for achieving maximum micro-hardness by PMND-EDM (Table 1) shows the tool specifications and selected process parameters values at different levels. The copper tool and the machined sample by PMND-EDM is shown in Fig. 2 while Table 2 shows the chemical composition and mechanical properties of the workpiece selected for experimentation.

\section{RESULTS AND DISCUSSION}

Micro-hardness testing for machined EN-31 samples was measured with the a Fischerscope instrument (HM2000S model) made in the USA. This instrument comprises an indenter (carbide), which indents the sample to be tested with respect to the load applied. Taguchi $\mathrm{L}_{9}$ OA was utilized for the design of experiments and the tests for micro-hardness were performed thrice for repeatability. In Taguchi analysis, signal-to-noise $(S / N)$ ratios were calculated for desired and undesired values. These output characteristics are generally of two types: higher-the-better (HB) and lower-the-better (LB). Since this study our aim aimed to increase the micro-hardness of the workpiece, the criteria to be considered is HB. The output signal to noise $(S / N)$ ratio considered for $\mathrm{HB}$ is given by Eq. (1) while the $\mathrm{S} / \mathrm{N}$ values along with output microhardness are given in Table 3.

$\mathrm{S} / \mathrm{N}$ is a technique of measurement in science and engineering to analyse the effect on output response relative to the target or nominal value under different noise conditions[dB]. In this study, the goal is to measure micro-hardness; therefore, the noise conditions are involved during experimentation.

A total of twenty-seven experiments were performed (three repeated for each set of process parameter condition):

$$
S / N \text { ratio }=-\log _{10}\left(\frac{1}{n} \sum_{i=1}^{n} \frac{1}{y_{i j}^{2}}\right),
$$

where $n$ is number of replications; and $y_{i j}$ observed response value.

The main effects and $S / N$ ratio for average microhardness and pooled ANOVA are given in Tables 4 and 5, respectively, for different process parameters. The effect of input parameters at different levels on micro-hardness value (average) was plotted, as shown in Fig. 3. It was observed that process parameters at $A_{1}, B_{2}, C_{3}$, and $D_{3}$ were most significant in enhancing the micro-hardness of an EN-31 workpiece machined by PMND-EDM. 
Table 3. The experimental results for micro-hardness by PMNDEDM as per Taguchi $L_{9} O A$

\begin{tabular}{ccccccccc}
\hline Exp. & \multicolumn{9}{c}{ Parameter trial condition } & \multicolumn{4}{c}{ Micro-hardness } & S/N \\
\cline { 2 - 8 } No. & A & B & C & D & R1 & R2 & R3 & [dB] \\
\hline 1 & 2 & 2 & 15 & 0.4 & 175 & 100.25 & 338.93 & 41.52 \\
\hline 2 & 2 & 5 & 20 & 0.5 & 450 & 350.78 & 345.08 & 49.69 \\
\hline 3 & 2 & 8 & 25 & 0.6 & 505.63 & 501.78 & 540.89 & 52.47 \\
\hline 4 & 3 & 5 & 15 & 0.6 & 59.37 & 45.96 & 50.26 & 32.39 \\
\hline 5 & 3 & 8 & 20 & 0.4 & 112.23 & 259 & 189 & 42.13 \\
\hline 6 & 3 & 2 & 25 & 0.5 & 132.23 & 55.63 & 62.38 & 34.96 \\
\hline 7 & 4 & 8 & 15 & 0.5 & 148.96 & 192.85 & 200.56 & 43.15 \\
\hline 8 & 4 & 2 & 20 & 0.6 & 237 & 215 & 350.22 & 46.23 \\
\hline 9 & 4 & 5 & 25 & 0.4 & 201 & 222.37 & 245 & 45.11 \\
\hline
\end{tabular}

Overall mean Vickers micro-hardness $(\overline{H V})=232.86$ load of micro-hardness measurements $300 \mathrm{~N} / 20 \mathrm{~s}$

The force applied for micro-hardness testing was $300 \mathrm{~N} / 20 \mathrm{~s}$ with the Fischer micro-hardness machine. The other results obtained were indentation modulus, mean value, confidence interval, and range for microhardness value. Parameter A (Tool type) at Level 1 was most significant in increasing the micro-hardness value of the machined EN-31 sample, as shown in Fig. 3a. At this level, the dielectric medium dispersion from the tool tip was found to be very suitable. Due to this proper dispersion, stable discharging was observed at the inter-electrode gap (IEG), which results in higher values of micro-hardness. The signalto-noise ratio $(S / N)$ in the graph also shows the same trend. Furthermore, the flow rate was found to be most influential at $2^{\text {nd }}$ level in increasing the microhardness value, as shown in Fig. 3b. At this level, the flow rate of the dielectric medium at $10 \mathrm{ml} / \mathrm{min}$ was optimum in providing suitable normal discharges at the machining zone along with powder additives, which results in a higher value of micro-hardness. The micro-hardness value was found to be highest at the $3^{\text {rd }}$ level of powder additive (metallic) concentration $(25 \mathrm{~g} / \mathrm{l})$, as shown by the trend of plot in Fig. 3c. The micro-hardness value increased with respect to the increase in metallic powder concentration, which can be observed in Fig. 3c. A zinc carbide ( $\mathrm{ZnC}$ ) hard layer was formed over the top surface of the workpiece due to rich amount of zinc deposition at the melting and resolidification zone over the surface of the sample (Fig. 4). As stated, the pyrolysis of dielectric results in diffusion of oxygen and carbon, which also results in the formation of hard carbides and oxides over the top layer of the machined workpiece [18]. All these factors resulted in achieving the best micro-hardness value at the $3^{\text {rd }}$ level of the process parameter. Dielectric mist pressure at the $3^{\text {rd }}$ level $(0.6 \mathrm{MPa})$ was most
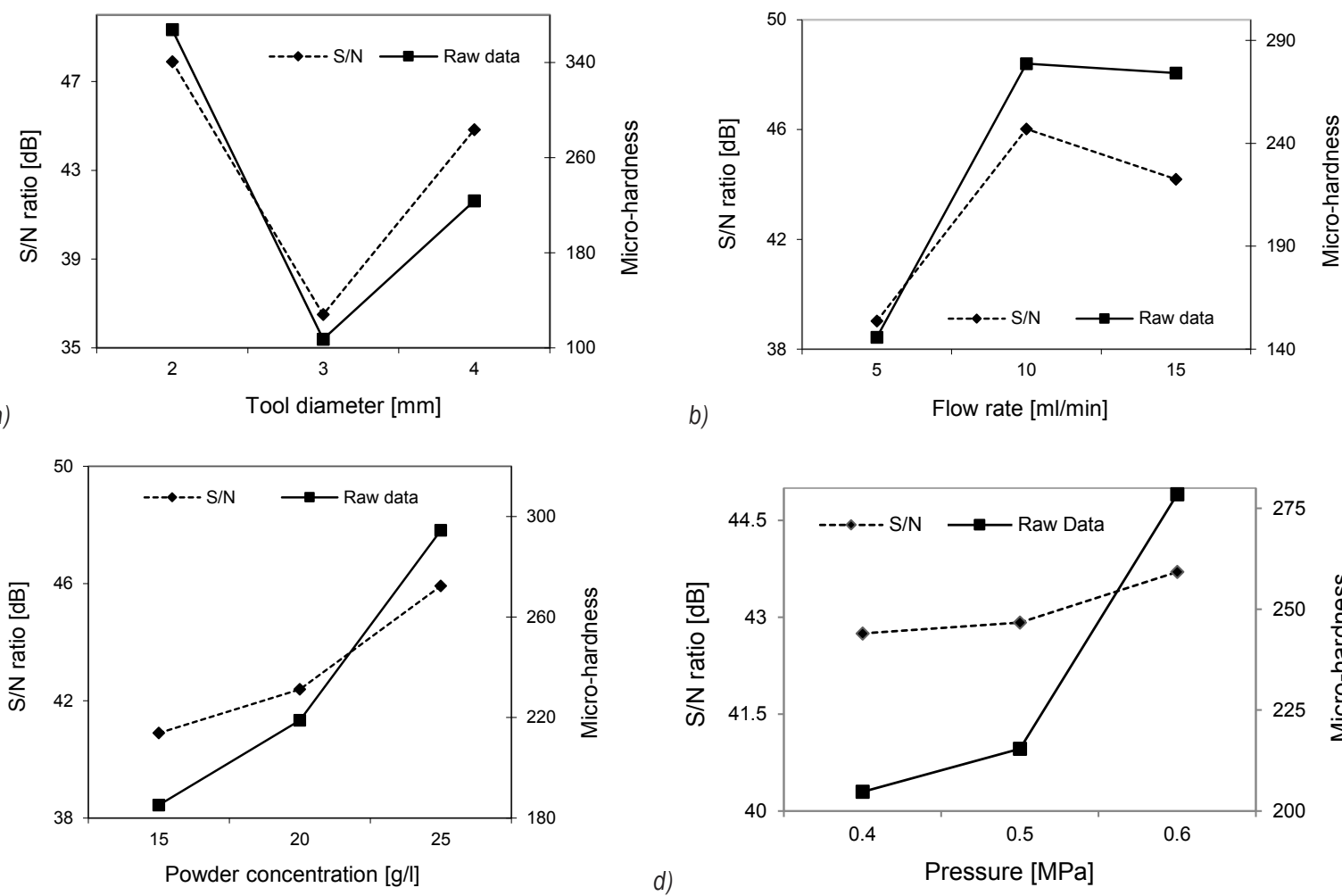

Fig. 3. Plot for micro-hardness vs. process parameters at different experimental conditions 
significant in enhancing the micro-hardness value, as shown in Fig. $3 \mathrm{~d}$, and the $S / N$ also shows the same trend in the plot. The trend displayed shows that the micro-hardness value increased with increase in the mist flow pressure. The excellent debris removal and cooling effect over the machined sample at this mist pressure resulted in achieving the maximum microhardness value at the sample surface.

The microstructure of the machined workpiece changes with there-crystallization phenomenon due to rapid heating and cooling during the machining process [19]. The shape of the material grains and, subsequently, the surface properties of the machined workpiece are determined by the heating and cooling rates.

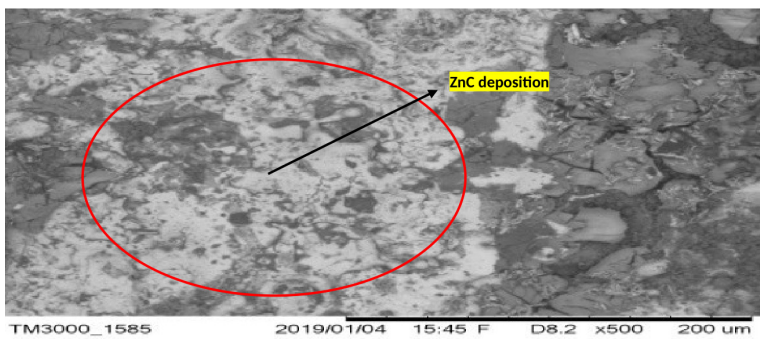

Fig. 4. ZnC layer formation over the machined sample

The average depth of the measured eroded holes $(60 \mu \mathrm{m})$ of the machined workpiece was measured with the help of vision inspection instrument. The cross-section of the machined surface was also analysed for the study of micro-hardness. Fig. 5 shows the recast layer at the top altered surface due to the melting and resolidification of the molten material. Due to changes in chemical composition and rapid cooling by flushing, there was a metallurgical structural change. A heat-affected zone was found below the recast layer due to heat generated by the plasma at the inter-electrode gap (IEG).
The white layer indicated the metallographic phase due to adequate carbon present, which results in the formation of $\mathrm{ZnC}$ deposits $(10 \mu \mathrm{m})$ along with the solidified molten material while comparison was also made with the machined sample without metallic powder, and there was a negligible metallurgical transformation as shown in Fig. 6.

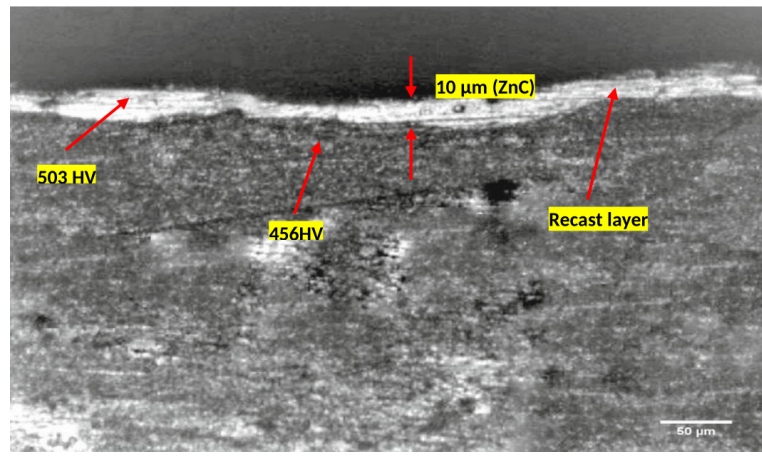

Fig. 5. SEM micrograph of cross section with average values of micro-hardness

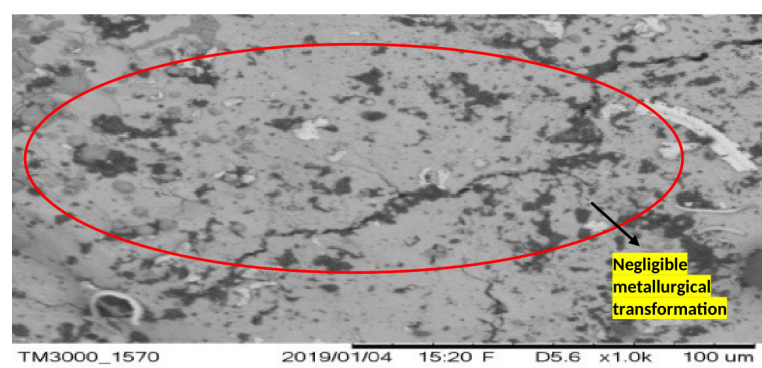

Fig. 6. SEM micrograph of machined sample by EDM without metallic powder

Scanning electron microscopy was performed for further analysis of the machined workpieces. Zinc metallic powder deposits at the resolidification process over the machined surface can be seen in Fig. 7 at different magnification factors. Metallic powder (zinc) in the dielectric and molten material migration

Table 4. Main effects table for micro-hardness

\begin{tabular}{|c|c|c|c|c|c|c|c|c|c|}
\hline \multirow{2}{*}{$\begin{array}{l}\text { Process parameter } \\
\text { Type of data }\end{array}$} & \multicolumn{2}{|c|}{ Level } & \multirow{2}{*}{$\begin{array}{c}\text { Tool diameter }(\mathrm{A}) \\
\text { Raw data }\end{array}$} & \multicolumn{2}{|c|}{ Flow rate $(\mathrm{B})$} & \multicolumn{2}{|c|}{ Powder concentration (C) } & \multicolumn{2}{|c|}{ Pressure(D) } \\
\hline & & S/N Ratio & & S/N Ratio & Raw data & S/N Ratio & Raw data & S/N Ratio & Raw data \\
\hline \multirow{3}{*}{$\begin{array}{l}\text { Average values } \\
\text { (\% micro-hardness) }\end{array}$} & L1 & 47.8 & 367.5 & 39 & 145.7 & 40.9 & 185.1 & 42.9 & 204.7 \\
\hline & L2 & 36.4 & 107.3 & 46 & 278.7 & 42.3 & 218.8 & 42.6 & 215.3 \\
\hline & L3 & 44.8 & 223.6 & 44.1 & 274.1 & 45.9 & 294.5 & 43.7 & 278.4 \\
\hline \multirow{2}{*}{$\begin{array}{l}\text { Main effects } \\
\text { (\% micro-hardness) }\end{array}$} & $\mathrm{L} 2-\mathrm{L} 1$ & -11.3 & -260.2 & 6.9 & 132.9 & 1.4 & 33.6 & -0.3 & 10.6 \\
\hline & $\mathrm{L} 3-\mathrm{L} 2$ & 8.3 & 116.3 & -1.8 & -4.6 & 3.5 & 75.6 & 1.0 & 63.0 \\
\hline $\begin{array}{l}\text { Differences } \\
(\mathrm{L} 3-\mathrm{L} 2)-(\mathrm{L} 2-\mathrm{L} 1)\end{array}$ & & 19.7 & 376.5 & -8.8 & -137.5 & 2.0 & 41.9 & 1.4 & 52.4 \\
\hline
\end{tabular}

${ }^{*} \mathrm{~L} 1, \mathrm{~L} 2, \mathrm{~L} 3$ represent levels 1, 2 and 3 respectively of parameters. (L2 - L1) is the average main effect when the corresponding parameter changes from Level 1 to Level 2. (L3 - L2) is the main effect when the corresponding parameter changes from Level 2 to Level 3. 
Table 5. Pooled ANOVA raw data and S/N data for micro-hardness

\begin{tabular}{|c|c|c|c|c|c|c|c|c|c|c|c|c|}
\hline Source & $\begin{array}{l}\text { SS } \\
\text { raw }\end{array}$ & $\begin{array}{l}\mathrm{SS} \\
\mathrm{S} / \mathrm{N}\end{array}$ & $\begin{array}{l}\text { DOF } \\
\text { raw }\end{array}$ & $\begin{array}{l}\text { DOF } \\
\text { S/N }\end{array}$ & $\begin{array}{c}\mathrm{V} \\
\text { raw }\end{array}$ & $\begin{array}{c}\mathrm{V} \\
\mathrm{S} / \mathrm{N}\end{array}$ & $\begin{array}{c}\text { F-ratio } \\
\text { Raw }\end{array}$ & $\begin{array}{c}\text { F-ratio } \\
\text { S/N }\end{array}$ & $\begin{array}{l}\text { SS' } \\
\text { raw }\end{array}$ & $\begin{array}{l}\text { SS' } \\
\text { S/N }\end{array}$ & $\begin{array}{l}\mathrm{P} \% \\
\text { raw }\end{array}$ & $\begin{array}{l}\mathrm{P} \% \\
\mathrm{~S} / \mathrm{N}\end{array}$ \\
\hline Tool diameter & 305936.46 & 208.81 & 2 & 2 & 152968.2 & 104.40 & 42.21 & 109.04 & 298690.1 & 206.90 & 53.46 & 62.78 \\
\hline Flow rate & 102445.57 & 79.03 & 2 & 2 & 51222.78 & 39.51 & 14.13 & 41.27 & 95199.25 & 77.12 & 17.04 & 23.40 \\
\hline $\begin{array}{l}\text { Powder } \\
\text { concentration }\end{array}$ & 56465.03 & 39.77 & 2 & 2 & 28232.52 & 19.88 & 7.79 & 20.76 & 49218.71 & 37.85 & 8.81 & 11.48 \\
\hline Pressure & 28569.57 & * & 2 & * & 14284.79 & * & 3.94 & - & 21323.25 & * & 3.81 & * \\
\hline Error & 65216.86 & 1.91 & 18 & 2 & 3623.15 & 0.95 & - & - & 94202.14 & 7.65 & 16.86 & 2.32 \\
\hline Total & 558633.51 & 329.54 & 26 & 8 & - & - & - & - & 558633.5 & 329.54 & 100 & 100 \\
\hline
\end{tabular}

* Significant at $95 \%$ confidence level, $\mathrm{F}$ critical (raw) $=3.55$ (tabular value), $\mathrm{F}$ critical $(\mathrm{S} / \mathrm{N})=19$ (tabular value), SS - Sum of Squares, DOF - Degree of Freedom, V - Variance, SS' - Pure sum of Squares P - Probability of obtaining the observed results of a test

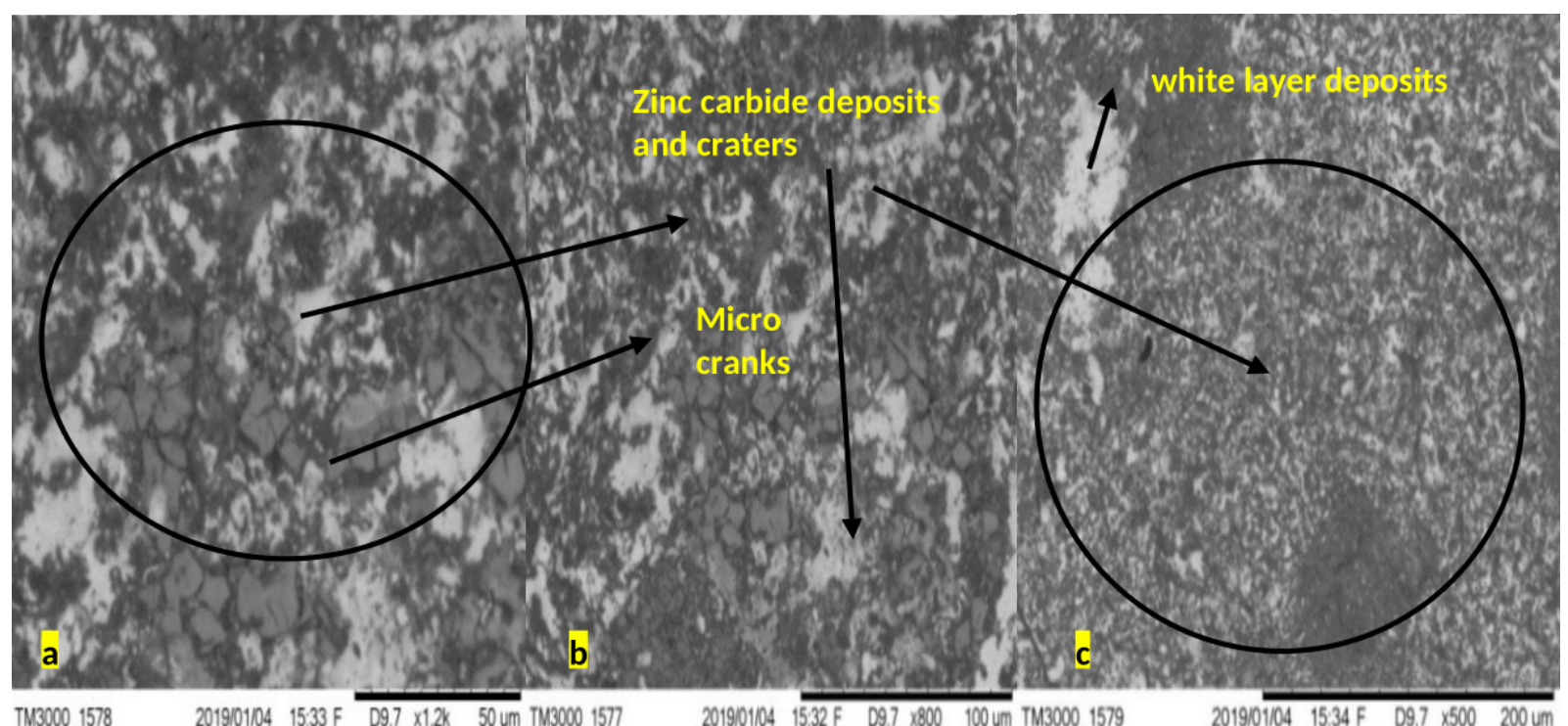

Fig. 7. SEM images of zinc deposits over the machined EN-31 sample by PMND-EDM at different magnification factors

from the tool electrode was also responsible for changes in the microstructure. Another observation was that the crater size was greater over the machined surface. A white layer of $\mathrm{ZnC}$ was formed and remained stable over the machined surface. This finegrained hard white layer was alloyed with molten material deposited from the tool electrode.

The hardest dark layer was seen at the top surface of the machined sample (Fig. 7). Dendritic features confronts that the phase transformation was also observed beneath the dark layer [13]. The alpha $(\alpha)$ phase of white layer occurred in the molten liquid phase. Primary discharges led to the formation of large craters, and pebble-type features were developed due to secondary discharges. Further increases in powder concentration also lead to the formation of small craters.

\subsection{Estimation of Performance Characteristics (Micro- Hardness)}

Micro-hardness response characteristics can be determined using Eq. (2), [20] and [21] as:

$$
\begin{aligned}
\text { Micro-hardness } & =\bar{A}_{1}+\bar{B}_{2}+\bar{C}_{3}+\bar{D}_{3}-3 \overline{H V} \\
& =520.7 \mathrm{HV} .
\end{aligned}
$$

The confidence interval of confirmation experiments can be determined using Eq. (3):

$$
C I_{C E}=\sqrt{F_{\alpha}\left(1, f_{e}\right) V_{e}\left[\frac{1}{n_{e f f}}+\frac{1}{R}\right]}=75.65 \text {. }
$$

The confidence interval of the population can be determined by Eq. (4):

$$
C I_{p o p}=\sqrt{F_{\alpha}\left(1, f_{e}\right) V_{e} / n_{e f f}}=37.82,
$$


where, $F_{\alpha}\left(1, f_{e}\right)$ is the $F$ ratio at the confidence level of $(1-\alpha)$ against DOF 1 .

$$
n_{\text {eff }}=\frac{F_{0.05}(1,18)=3.5546 \text { (Tabulated) }}{1+\left[\begin{array}{c}
\text { DOF associted in the estimate } \\
\text { of mean response }
\end{array}\right]}=9,
$$

where $N$ is the total number of experiments $(N=$ $27)$; treatment is 9 , repetition 3 , and sample size for confirmation experiments, $R=3$.

$$
\begin{aligned}
& V_{e}, \text { error variance }=3623.15(\text { Table } 5), \\
& f_{e}, \text { error DOF }=18(\text { Table } 5), \\
& F=3.5546 \text { (tabulated } F \text { value), }
\end{aligned}
$$

where

$$
F=\frac{\text { Variation between sample means }}{\text { Variation within the samples }} \text {. }
$$

This $F$ value is compared with the $F$ limit for respective DOF. If $F$ value is equal to or greater than the $F$-limit value (seen in Table 5), it can be said that significant differences exist between the sample means.

Therefore, micro-hardness is 520.7,

$$
C I_{C E}= \pm 75.65, C I_{P O P}= \pm 37.82
$$

The predicted optimal range of confidence interval of conformation experiments $\left(C I_{C E}\right)$ is:

$\left[\begin{array}{c}\text { Mean } \\ \text { micro- } \\ \text { hardness }\end{array}\right]-C I_{C E}<\left[\begin{array}{c}\text { micro- } \\ \text { hardness }\end{array}\right]<\left[\begin{array}{c}\text { Mean } \\ \text { micro- } \\ \text { hardness }\end{array}\right]+C I_{C E}$,

i.e. $445.05<$ micro-hardness $<596.35$.

The $95 \%$ conformation interval of the predicted mean is:

$\left[\begin{array}{c}\text { Mean } \\ \text { micro- } \\ \text { hardness }\end{array}\right]-C I_{P O P}<\left[\begin{array}{c}\text { micro- } \\ \text { hardness }\end{array}\right]<\left[\begin{array}{c}\text { Mean } \\ \text { micro- } \\ \text { hardness }\end{array}\right]+C I_{P O P}$,

i.e. $482.88<$ micro-hardness $<558.52$.

The confirmation tests for micro-hardness were performed by setting machining conditions at the optimal process parameters values given below:

- Tool diameter at level $1(2 \mathrm{~mm})$;

- Flow rate at level $2(10 \mathrm{ml} / \mathrm{min})$;

- Powder concentration at level $3(25 \mathrm{~g} / \mathrm{l})$;

- Dielectric mist pressure at level 3 (0.6 MPa);
The confirmation tests were run thrice to obtain the average value in order to reduce the percentage error in experimentations. The micro-hardness values achieved were $449.30 \mathrm{HV}, 510.39 \mathrm{HV}$, and $560.21 \mathrm{HV}$ respectively for the three trials and the average value was $506.63 \mathrm{HV}$.

(ISO standard: Vickers hardness numbers are reported as $506.63 \mathrm{HV} 300 \mathrm{~N} / 20$ seconds, where C (loading time) $=5 \mathrm{~s}$ indicates the time if it differs from $10 \mathrm{~s}$ to $15 \mathrm{~s})$.

\subsection{Confirmation Experiments}

The confirmation test was performed for microhardness at $\mathrm{A}_{1}, \mathrm{~B}_{2}, \mathrm{C}_{3}$, and $\mathrm{D}_{3}$ experimental conditions. The mean micro-hardness calculated was $506.21 \mathrm{HV}$ which lies within the confidence interval of predicted micro-hardness.

\subsection{Analysis for TWR}

The decrease in TWR was $18.80 \%$ by PMND-EDM as compared to near dry EDM (i.e., without metallic powder), as shown in Fig. 8.

The TWR ( $\mathrm{mg} / \mathrm{min})$ was measured with the formula:

$$
T W R=\left(T_{i}-T_{f}\right) / T_{m},
$$

where $T_{i}$ is the initial weight of the tool, $T_{f}$ is the final weight of tool, and $T_{m}$ is the machining time.

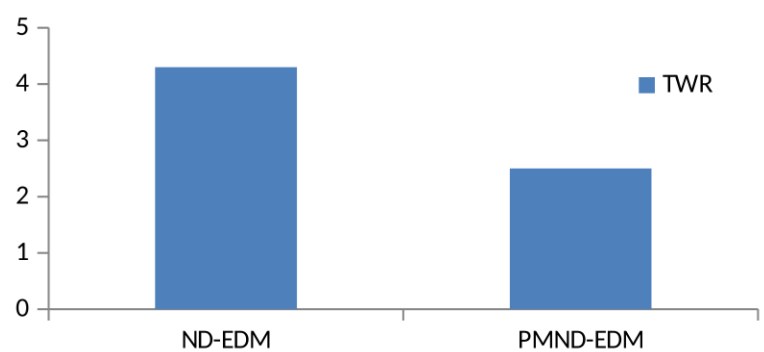

Fig. 8. Comparison for TWR between near dry EDM and PMND-EDM

The addition of conductive metallic powder leads to reduced breakdown voltage and increase in the interspace between the electrodes for electric discharge [22]. This phenomenon improves the stability of the machining process that caused a reduction in TWR. The dielectric fluid (LL-221) with added conductive powder has improved the efficiency of electrical discharging at the spark gap, preventing the tool electrode tip from further wear, as shown in Fig. 9. 
Heat dissipation was improved because the phenomena of abnormal discharge and short circuit were minimized. The amount of heat conducted to the tool was also reduced due to proper heat dissipation. This makes the material temperature go below its melting point, which consequently reduces TWR [16].

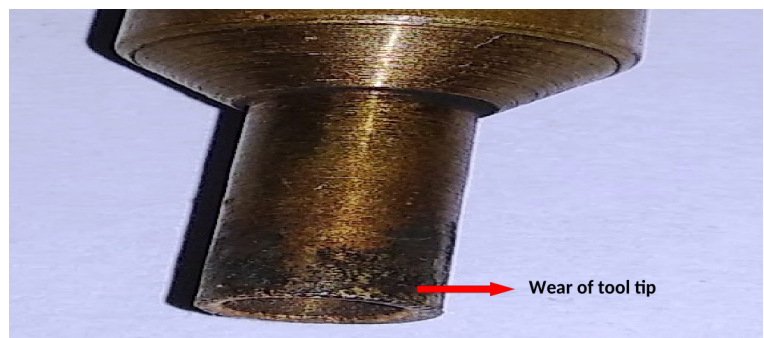

Fig. 9. Wear of tool electrodes tip after PMND-EDM process

\section{CONCLUSIONS}

This paper included investigations on micro-hardness of machined EN-31 samples by utilizing Taguchi $\mathrm{L}_{9} \mathrm{OA}$; a further ANOVA technique was implemented to study the effects of different process parameters on output response micro-hardness. The conclusions drawn after the research are as follows:

- It was concluded that the PMND-EDM method of machining at optimum input process parameters leads to the generation of machined parts with higher micro-hardness values.

- The requirement of a large quantity of dielectric oil was eliminated as only a minute amount of dielectric oil was required for machining hard metals.

- It was observed that optimum parameter condition at A1, B2, C3, and D3 were most dominant in achieving the maximum micro-hardness of machined EN-31 die steel workpiece.

- Confirmation experiments revealed that the highest value of micro-hardness was found to be $506.63 \mathrm{HV}$ at optimized input process parameters.

- The predicted optimal range of confidence interval of conformation experiments (CICE) for micro-hardness was: $445.05<$ micro-hardness $<$ 596.35 .

- The $95 \%$ conformation interval of the predicted mean for micro-hardness was: $482.88<$ microhardness $<558.52$.

- A layer of hard zinc carbide hard was deposited over the surface of the machined sample which leads to a higher value of micro-hardness.
- The experimental results were validated by confirmation of experiments, and the obtained output results were within the permissible results.

- The metallic powder additives aids in the generation of a stable and more energized spark due to increased thermal conductivity at the interelectrode gap.

\section{REFERENCES}

[1] Zhao, W.S., Meng, Q.G.,Wang, Z.L. (2002). The application of research on powder mixed EDM in rough machining. Journal of Materials Processing Technology, vol. 129, no. 1-3, p. 30-33, DOI:10.1016/S0924-0136(02)00570-8.

[2] Gao, Q., Zhang, Q.H., Zhang, J.H. (2009). Experimental study of powder-mixed near dry electrical discharge machining. Chinese Journal of Mechanical Engineering, vol. 45, no. 1, p.169-175, DOI: 10.3901/JME.2009.11.169.

[3] Kumar, S., Batra, U. (2012). Surface modification of die steel materials by EDM method using tungsten powder-mixed dielectric. Journal of Manufacturing Processes, vol. 14, no. 1, p. 35-40, D0l:10.1016/j.jmapro.2011.09.002.

[4] Zain, Z.M., Ndakiman, M.B., Khan, A.A., Ali, M.Y. (2014). Improving micro-hardness of stainless steel through powdermixed electrical discharge machining. Proceedings of the Institution of Mechanical Engineers, Part C: Journal of Mechanical Engineering Science, vol. 228, no. 18, p. 33743380, DOI:10.1177/0954406214530872.

[5] Li, L., Zhao, L., Li, Z.Y., Feng, L., Bai, X. (2016).Surface characteristics of Ti-6Al-4V by SiC abrasive-mixed EDM with magnetic stirring. Materials and Manufacturing Processes, vol. 32, no. 1, p. 83-86, Dol:10.1080/10426914.2016.11510 43.

[6] Gill, A.S., Kumar, S. (2016). Surface roughness and microhardness evaluation for EDM with Cu-Mn powder metallurgy tool. Materials and Manufacturing Processes, vol. 31, no. 4, p. 514-521, DOI:10.1080/10426914.2015.1070412.

[7] Rahul, Datta, S., Biswal, B.B., Mahapatra, S.S. (2017). A novel satisfaction function and distance-based approach for machining performance optimization during electro-discharge machining on super alloy Inconel 718. Arabian Journal for Science and Engineering, vol. 42, no. 5, p. 1999-2020, DOI:10.1007/s13369-017-2422-5.

[8] Talla, G., Gangopadhyay, S., Biswas, C.K. (2017). Influence of graphite powder mixed EDM on the surface integrity characteristics of Inconel 625. Particulate Science and Technology, vol. 35, no. 2, p. 219-226, D0l:10.1080/027263 51.2016.1150371.

[9] Amorim, F.L., Dalcin, V.A., Soares, P., Mendes, L.A. (2017). Surface modification of tool steel by electrical discharge machining with molybdenum powder mixed in dielectric fluid. The International Journal of Advanced Manufacturing Technology, vol. 91, no. 1-4, p. 341-350, D0l:10.1007/ s00170-016-9678-x.

[10] Tripathy, S., Tripathy, D.K. (2017). An approach for increasing the micro-hardness in electrical discharge machining by adding conductive powder to the dielectric. Materials Today: 
Proceedings, vol. 4, no. 2, p. 1215-1224, D0I:10.1016/j. matpr.2017.01.140.

[11] Gill, A.S., Kumar, S. (2018). Investigation of micro-hardness in electrical discharge alloying of En31 tool steel with $\mathrm{Cu}-\mathrm{W}$ powder metallurgy electrode. Arabian Journal for Science and Engineering, vol. 43, no. 3, p. 1499-1510, D0l:10.1007/ s13369-017-2960-x.

[12] Sahu, S.K., Jadam, T., Datta, S., Dhupal, D., Nandi, G. (2018). Application of SiC power added in kerosene dielectric media for electro-discharge machining of Inconel 718 super alloys: effect of powder concentration. Materials Today: Proceedings, vol. 5, no. 9, p. 20297-20305, D0l:10.1016/j. matpr.2018.06.402.

[13] Öpöz, T.T., Yaşar, H., Ekmekci, N., Ekmekci, B. (2018). Particle migration and surface modification on Ti6Al4V in SiC powder mixed electrical discharge machining. Journal of Manufacturing Processes, vol. 31, p. 744-758, D0l:10.1016/j. jmapro.2018.01.002.

[14] Chundru, V.R., Koona, R., Pujari, S.R. (2018). Surface modification of Ti6Al4V alloy using EDMed electrode made with nano- and micron-sized TiC/Cu powder particles. Arabian Journal for Science and Engineering, vol. 44, no. 2, p. 14251436, DOI:10.1007/s13369-018-3561-z.

[15] Kumar, M., Datta, S., Kumar, R. (2019). Electro-discharge machining performance of Ti-6Al-4V alloy: Studies on parametric effect and phenomenon of electrode wear. Arabian Journal for Science and Engineering, vol. 44, no. 2, p. 15531568, D0l:10.1007/s13369-018-3632-1.

[16] Bai, X., Zhang, Q.H., Yang, T., Zhang, J.H., Tan, J. (2013). Research on tool wear rate of powder mixed near dry electrical discharge machining. Advanced Materials Research, vol.
652-654, p. 2222-2227, D0I:10.4028/www.scientific.net/ AMR.652-654.2222.

[17] Yuvaraj, T., Suresh, P. (2019). Analysis of EDM process parameters on Inconel 718 using the grey-Taguchi and TOPSIS methods. Strojniški vestnik - Journal of Mechanical Engineering, vol. 65 , no. 10 , p. 557-564, D0l:10.5545/svjme.2019.6194.

[18] Talla, G., Gangopadhyay, S., Biswas, C.K. (2016).Effect of powder- suspended dielectric on the EDM characteristics of Inconel 625. Journal of Material Engineering and Performances, vol. 25, no. 2, p. 704-717, D0l:10.1007/ s11665-015-1835-0.

[19] Singh, G., Singh, G., Singh, K., Singla, A. (2017). Experimental studies on material removal rate, tool wear rate and surface properties of machined surface by powder mixed electric discharge machining. Materials Today: Proceedings, vol. 4, no. 2, p. 1065-1073, D0I:10.1016/j.matpr.2017.01.121.

[20] Walia, R.S., Shan, H.S., Kumar, P. (2006). Multi-response optimization of CFAAFM process through Taguchi method and utility concept. Materials and Manufacturing Processes, vol. 21, no. 8, p. 907-914, DOl:10.1080/10426910600837814.

[21] Brar, B.S., Walia, R.S., Singh, V.P. (2015). Electrochemicalaided abrasive flow machining (ECA2 FM) process: a hybrid machining process. International Journal of Advanced Manufacturing Technology, vol. 79, no. 1-4, p. 329-342, DOl:10.1007/s00170-015-6806-y.

[22] Jeswani, M.L. (1981). Effects of the addition of graphite powder to kerosene used as the dielectric fluid in electrical discharge machining. Wear, vol. 70, no. 2, p. 133-139, D0l:10.1016/0043-1648(81)90148-4.Valibunu estiust arbit. Viverimur potebus octus, nont? Urorbis, nos, quit. Ivivena, 